\title{
Nanographene's Influence on a Recycled High-density Polyethylene/Poplar Wood Flour Nanocomposite
}

\author{
Jafar Ghaje Beigloo, ${ }^{\mathrm{a}}$ Habibollah Khademi Eslam, ${ }^{\mathrm{a}, *}$ Amir Hooman Hemmasi, ${ }^{\mathrm{a}}$ \\ Behzad Bazyar, ${ }^{\mathrm{a}}$ and Ismaeil Ghasemi ${ }^{\mathrm{b}}$
}

\begin{abstract}
The effect of nanographene amount was evaluated relative to the physical, mechanical, thermal, and morphological features of wood-plastic composites. Composites were prepared using recycled polyethylene (high-density polyethylene), nanographene, and wood-flour. The amount of $80 \%$ of polymer matrix and $20 \%$ of wood flour, and nanographene at four weight levels of $0.5 \%, 1.5 \%$, and $2.5 \%$, were used. An internal mixture was utilized for making the samples. The results showed that with the 0.5 wt\% increase of the amount of nanographene, the tensile and flexural strengths, the flexural and tensile modulus and the notched impact strength composite increased. With the addition of $2.5 \mathrm{wt} \%$ nanographene, these properties decreased. With the increase of the level of nanographene by $2.5 \mathrm{wt} \%$, water absorption and the thickness swelling of the composite decreased. With the increase of the level of nanographene, the level of residue ash and thermal stability also increased. Scanning electron microscope images showed that the samples with $0.5 \mathrm{wt} \%$ nanographene had less holes and a smoother surface compared to the other samples.
\end{abstract}

Keywords: Recycled high-density polyethylene; Nanographene; Wood-plastic composite

Contact information: a: Department of Wood and Paper Science Technology, College of Agriculture and Natural Resources, Science and Research Branch, Islamic Azad University, Tehran, Iran; b: Iran Polymer and Petrochemical Institute, P.O. Box 14965/115, Tehran, Iran;

*Corresponding author: hkhademieslam@gmail.com

\section{INTRODUCTION}

In recent years, there has been a growing interest in using natural fibers as the reinforcing factors in plastic material composites (Hornsby et al. 1997; Tripathy et al. 2000; Zafeiropoulos et al. 2001). Natural fibers have properties, such as low price, low density, non-toxic nature and recyclability, that have given rise to the increase of interest in building composites at a low price and weight (Saheb and Jog 1999). Every day, a noticeable amount of plastic trash enters into the environment. Generally, polyethylene (PE), polypropylene (PP), polyethylene terephthalate (PET), polystyrene (PS), and polyvinyl chloride (PVC) are the main parts of plastics in urban solid wastes (Najafi 2013). The primary studies show that approximately $46 \%$ of urban solid trashes in Tehran are formed of the light polyethylene (26\%) and high-density polyethylene (20\%). Considering the fact that separation of the plastic is costly, using them in the form of a mixture has always been an option. In contrast, the type and combination of existing plastics in urban trashes in each region is different, which should be taken into consideration in plastics recycling. One way to recycle the plastics is to use them in building wood-plastic composites. Using nano materials, it is possible to improve the properties of composites existing in this industry and produce new products with a further high added value and 
efficiency. Today, using nanotechnology to reinforce the composites has attracted much attention. Among the type of nanomaterials that are used in making wood-plastic composites, nanographene has received serious attention in recent years due to having exceptional mechanical, thermal, optical, and electrical properties (Dato et al. 2009; Cardinali et al. 2012; Sheshmani and Amiri 2013). The outstanding properties of nanographene in comparison to poly(vinylidene fluoride) have been reflected in the nanocomposite graphene/polymer that shows a high mechanical and thermal strength against gas, electrical conductivity, and fire resistance compared with the pure polymer (Balandin et al. 2008; Ansari and Giannelis 2009; Potts et al. 2011). Research shows that the improvement and increase of the mechanical and electrical properties nanographenepolymer composites is much greater than nanoclays and/or other nanocomposites (Kuilla et al. 2010).

The mechanical properties of such compounds are strongly affected by the morphology of the phases and their seasonal characteristics. One of the most common ways to correct this is to use compatibilizers. Adding the appropriate compatibilizers to the polymer composition while reducing the interfacial tension between the phases, results in the compatibility and miscibility of the two polymers. In addition to better dispersion of phases, it results in interfacial adhesion and ultimately improved mechanical properties. In this regard, Kord (2016) investigated the effect of the filler and compatibilizer amount on the thermal properties of composites made from wood flour and heavy polyethylene. The results showed that the addition of the compatibilizer increased the thermal stability and the crystallinity of the composite.

Sheshmani and Amiri (2013) dealt with wood-plastic composites, using spruce wood flour and PP polymer materials along with graphene nanosheets (GNs). Their results showed that when nanographene was used at the level of $8 \mathrm{wt} \%$, the flexural and tensile features reached their maximum value, whereas in the case of greater quantities, due to agglomeration and lack of proper transfer of tension, the physical and mechanical properties of composites reached their minimum values. Chaharmahali et al (2014) studied the effect of using graphene nanoparticles on the physical and mechanical properties of composites made of bagasse fibers and PP. They learned that the greatest amount of tensile and flexural strength was obtained in the samples made with $0.1 \%$ of nanographene. The increase of the percentage of fibers from 15 to $30 \%$ gave rise to the increase of flexural and tensile properties, but the impact strength decreased. In addition, at the level of $15 \%$ of fibers, adding nanographene improved the durability against the thermal destruction of composites. However, at the level of $30 \%$ fibers, the reverse results were obtained. Gedler et al. (2012) reviewed the thermal durability of graphene polycarbonate nanocomposites and found that polycarbonate in nitrogen conditions holds single-stage destruction, whereas in the conditions of the atmosphere, it shows three-stage destruction. Additionally, the thermal durability of foamed composites increased noticeably. An et al. (2012) studied the effect of adding nanographene to composites resulting from cellulose acetate. Their research showed that the dynamic-mechanical modulus of composites increases by adding nanographene. This research was conducted to review the effect of nanographene amount on physical, mechanical, thermal, and morphological features of wood-plastic composites. In this study, the effect of the amount of nanographene on physical, mechanical, thermal and morphological features of wood-plastic composites was reviewed. 


\section{EXPERIMENTAL}

\section{Materials}

Wood flour

For this purpose, some trunks of (Populus alba) poplar were cut (Karaj, Iran). Afterward, the pieces were converted into straw, and then by using a laboratory mill (I 2W/25; Iran Sanat Company, Alboz, Iran) they were converted into wood flour. Using a lab sieve, they were meshed. In this study, the wood flour passed through sieve of 50-mesh screen size and the remains on the sieve that passed through a 70-mesh screen size were used. Afterward, using a laboratory oven, the moisture content of the samples was decreased to approximately $1 \%$.

\section{Polyethylene}

High-density polyethylene (HDPE), a product of Shazand Arak Petrochemicals (Arak, Iran) with the brand of HD5218, with melt flow index (MFI) of $18 \mathrm{~g} / 10 \mathrm{~min}$ and density of $0.956 \mathrm{~g} / \mathrm{cm}^{3}$ were used in this research. To simulate the effect of recycling, polymers underwent the effect of three-stage thermodynamic destruction, using the two spiral extruders (Brabender, Duisburg, Germany). The MFI of recycled HDPE samples was measured based on the ASTM D1238-04 (2004) standard using a Gottfert/M1-4 device (Rheometer Manufacturers, Buchen, Germany).

\section{Coupling agent}

To create compatibility between wood flour and recycled polyethylene, maleic anhydride grafted polyethylene (MAPE; PEGW $2203 \%$; Arya Polymer Company, Isfahan, Iran) with MFI of $7 \mathrm{~g} / 10 \mathrm{~min}$ and $0.964 \mathrm{~g} / \mathrm{cm}^{3}$ was used.

\section{Nanographene}

A 0-4 type nanographene (Graphene Supermarket Company, Ronkonkoma, NY, USA) was purchased. Some of its particulars are presented in Table 1.

Table 1. Nanographene Specifications

\begin{tabular}{|c|c|c|c|c|}
\hline $\begin{array}{c}\text { Specific } \\
\text { Surface }\left(\mathbf{M}^{2} / \mathbf{g}\right)\end{array}$ & Color & Purity (\%) & $\begin{array}{c}\text { Medium } \\
\text { Thickness } \\
(\mathbf{m m})\end{array}$ & $\begin{array}{c}\text { Particles } \\
\text { Length }(\mu \mathrm{m})\end{array}$ \\
\hline More than 15 & Black & 98.5 & 60 & 3 to 7 \\
\hline
\end{tabular}

\section{Material mixture}

In this research, the polymer matrix (recycled HDPE), wood flour, coupling agent (MAPE), and nanographene were used in accordance with the determined combinations in Table 1.

In regards to the treatments under study (Table 2), to have the mixture of the polymer matrix with wood flour and nanographene, the internal mixture device HAAKE SYS 9000 (Hake, De Soto, MO, USA) was used at the Iran Polymer and Petrochemicals Research Institute. The mixing temperature was $150{ }^{\circ} \mathrm{C}$, the mixing speed was $60 \mathrm{rpm}$, and the total mixing time lasted 8 min. 
Table 2. Weight Percentage of Forming Components for the Combination of Different Treatments of Wood-plastic Composite

\begin{tabular}{|c|c|c|c|c|}
\hline Treatment Code & $\begin{array}{c}\text { Wood Flour } \\
(\%)\end{array}$ & $\begin{array}{l}\text { Recycled } \\
\text { HDPE (\%) }\end{array}$ & MAPE (\%)* & $\begin{array}{c}\text { Nanographene } \\
(\%)^{\star}\end{array}$ \\
\hline A 1 & 20 & 80 & 3 & 0 \\
\hline A 2 & 20 & 80 & 3 & 0.5 \\
\hline B 1 & 20 & 80 & 3 & 1.5 \\
\hline B 2 & 20 & 80 & 3 & 2.5 \\
\hline
\end{tabular}

${ }^{*}$ Based on total weight of wood-plastic composite

After the mixing process, the outlet materials from the extruder were milled using a WIEFER semi-industrial mill (WG-LS 200/200; EIESER, Hamburg, Germany) and the resulting granules from each combination were made using a laboratory press (Toyoseiki Company, Tokyo, Japan) at $200{ }^{\circ} \mathrm{C}$ for 4 min under $25 \mathrm{MPa}$ pressure.

Then, the samples were cooled to $80{ }^{\circ} \mathrm{C}$ and during the cooling the press pressure continued. Before doing the physical and mechanical tests, the built samples were placed in climatic conditions (temperature of $20 \pm 2{ }^{\circ} \mathrm{C}$ and relative humidity of $65 \pm 5 \%$ ). Then, they underwent testing in accordance with ASTM D638-10 (2010), ASTM D747-10 (2010), ASTM D256-10 (2010), and ASTM D7031-04 (2004) standards. To measure each of the properties, five repetitions were considered.

Prior to the physical and mechanical tests, the built samples were placed in Colima conditions for two weeks to achieve a balanced humidity.

TGA test

Using a thermal analyzer (TGA Q50; PL-150, Agilent Technologies, Santa Clara, CA, USA), thermogravimetric analysis (TGA) was made for $7 \mathrm{mg}$ of testing sample in the thermal range of 25 to $700{ }^{\circ} \mathrm{C}$ at a rate of $15^{\circ} \mathrm{C} / \mathrm{min}$ speed.

\section{Fourier transform infrared (FTIR) spectroscopy}

The spectra were studied using a spectrometer device (q600; TA Instruments, New Castle, DE, USA). The acquisition conditions were: spectral width of 4000 to $400 \mathrm{~cm}^{-1}$, number of scans 10 , and resolution $4 \mathrm{~cm}^{-1}$.

Scanning electron microscopy (SEM)

The morphology of composites was characterized using scanning electron microscopy (SEM, Model AIS2100; Seron Technology, Gyeonggi-do, Korea) set at a 0.5 $\mathrm{kV}$ to $30 \mathrm{kV}$ accelerating voltage.

\section{Statistical analysis}

Data analysis was performed using SPSS software (IBM Software, v.11.5, Armonk, NY, USA) in a randomized statistical plan under a factorial design, and eventually a comparison and grouping were performed via the Duncan test using a 95\% confidence level. 


\section{RESULTS AND DISCUSSION}

\section{Melt Flow Index}

The MFI is measured in specific thermal and sectional conditions. This feature shows the fluidity of the polymer. The MFI does not display the viscoelastic behavior of the polymer. The results showed that the MFI of HDPE increased after recycling three times from $18 \mathrm{~g} / 10 \mathrm{~min}$ for pure polymer to $35.0 \mathrm{~g} / 10 \mathrm{~min}$. The frequency increase of recycling under the influence of thermodynamic factors caused reduction in the crystallinity and average molecular weight of polyethylene (increase of MFI). For HDPE, similar results were reported by other researchers (Abad et al. 2004; Pinheiro et al. 2004).

\section{Mechanical Properties}

In this research, the effect of nanographene amount in four different levels $(0,0.5$, 1.5 , and $2.5 \%$ ) was evaluated. The $\mathrm{F}$ amount and significance level are displayed in Table 3 . The results of Table 3 show that the effect of nanographene on the tensile strength and modulus, flexural strength and modulus, notched impact strength, water absorption, and short term thickness swelling was significant at the confidence level of $95 \%$.

The mechanical features of composites are under the influence of the matrix features, filler (quality of dispersion, amount, shape, etc.), the quality of intersection in the polymer mixture, and also between the polymer matrix and lignocellulosic material. In general, lignocellulosic materials, due to their polar nature, during mixing with a non-polar polymer matrix tends to agglomerate and thus, they do not have a smooth dispersion. This issue and also weak cohesiveness in the intersection part, results in decreased physical and mechanical features of the wood-plastic composite.

In addition to the fact that the coupling agents, such as compounds with maleic acid, increase the smooth distribution of lignocellulosic materials in a polymer matrix, other factors related to preparation, including the type of extruders, screw rotation speed, have a noticeable role in this regard (Klason et al. 1984; Bengtsson et al. 2007; Le Baillif and Oksman 2009; Ghani et al. 2011).

Table 3. Variance Analysis (F-Value and significance level) of the Effect of Nanographene on Strengths

\begin{tabular}{|c|c|c|c|c|c|c|c|}
\hline & 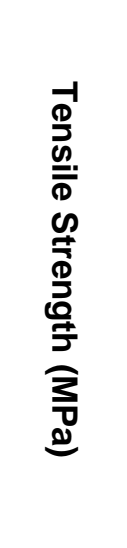 & 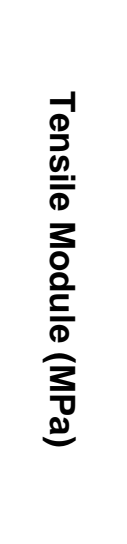 & 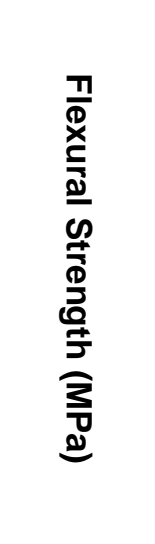 &  & 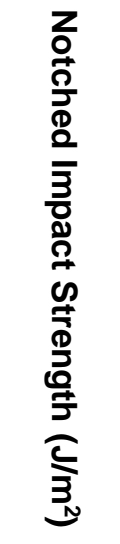 &  &  \\
\hline Nanographene & $4.630^{*}$ & $6.008^{*}$ & $199.063^{*}$ & $6.690^{*}$ & $4.353^{*}$ & $35.525^{\star}$ & $21.058^{*}$ \\
\hline
\end{tabular}




\section{Effect of nanographene amount on tensile strength and modulus}

The trend of the composite tensile strength at different levels of nanographene is displayed in Fig. 1. The highest and lowest average strength was observed in the $0.5 \%$ sample (with $15.5 \mathrm{MPa}$ ) and the $0 \%$ sample (14.7 MPa), respectively.

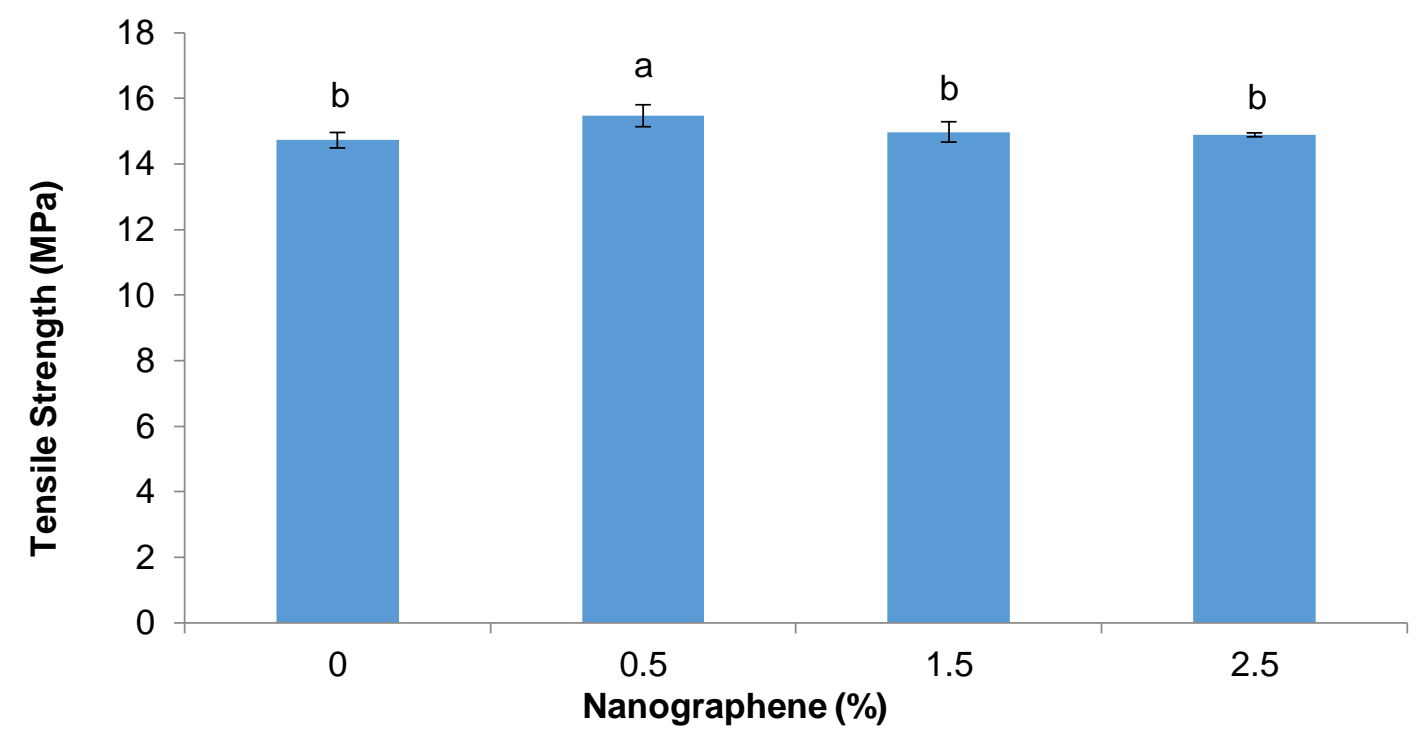

Fig. 1. Effect of the amount of nanographene on tensile strength

The trend of changes in the composite tensile modulus at different levels of nanographene is shown in Fig. 2. The highest and lowest average tensile modulus was observed in the $0.5 \%$ sample $(288.39 \mathrm{MPa})$ and $0 \%$ sample $(221.47 \mathrm{MPa})$, respectively.

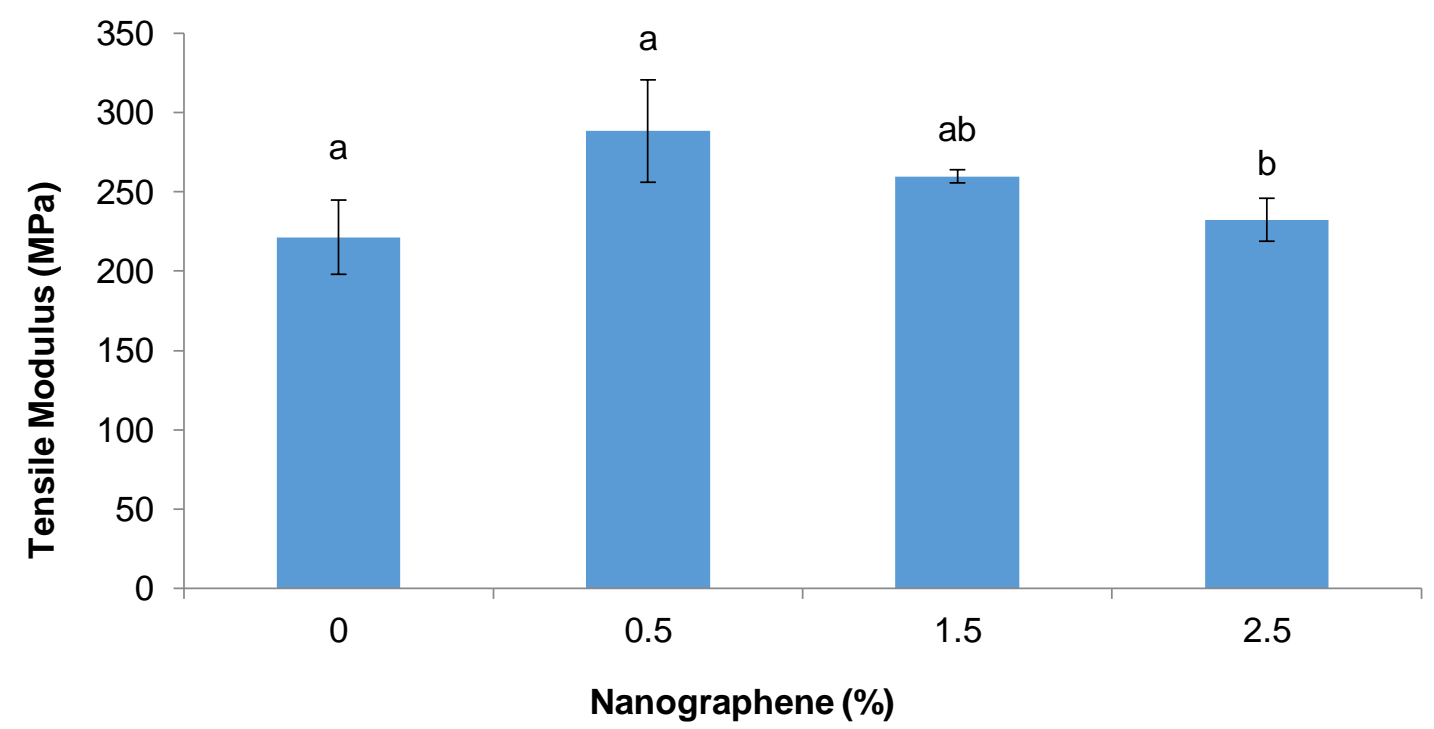

Fig. 2. Effect of the amount of nanographene on tensile modulus

The tensile strength is the greatest tensile power in which an object will bear prior to breaking. In this research, it was observed that with the increased nanographene amount $(0.5 \mathrm{wt} \%)$, the composite tensile strength and modulus increased. Then, with the addition 
of 2.5\% nanographene, it decreased. Sheshmani and Amiri (2013) showed that with the $0.8 \%$ increase in the percentage of nanographene in a polypropylene composite, the tensile modulus will increase and with an increase in the amount of nanographene, the tensile modulus decreases (Sheshmani and Amiri 2013). In each system of a nanocomposite, there is an optimal amount of nanoparticles to achieve the highest modulus and strength.

This optimal level is under the influence of many parameters related to nanoparticles and the matrix, such as the specific level of particles, cohesiveness among the particles and matrix at intersection, proper dispersion and distribution, and conditions of the process. Thus, as the graphene had a high specific level, in the event of using this material at high quantity, it will cause agglomeration of particles and reduction in the modulus.

\section{Effect of nanographene amount on flexural strength}

In the flexural strength, as a result of applied force, one side of the sample is stretched and the other side is compressed (Gao et al. 2008).

The trend of changes of the composite's tensile strength resulting from different levels of nanographene is displayed in Fig. 3. The highest and lowest average flexural strength was observed in the $0.5 \%$ sample $(22.0 \mathrm{MPa})$ and the $0 \%$ sample $(18.4 \mathrm{MPa})$.

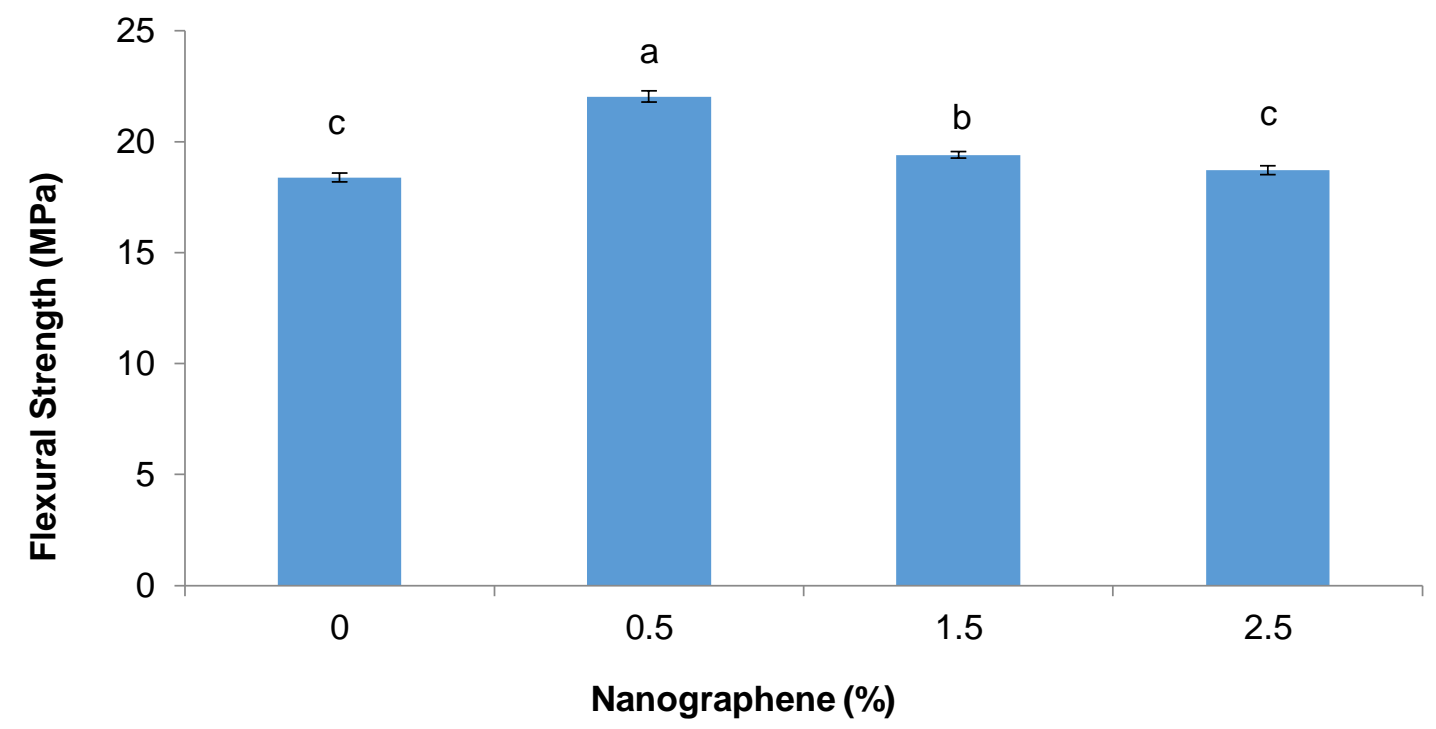

Fig. 3. The effect of the amount of nanographene on flexural strength

In this research, it was observed that with an increased amount of nanographene of $0.5 \mathrm{wt} \%$, the composite flexural strength of the wood-plastic composite increased and then when nanographene increased to $2.5 \mathrm{wt} \%$, it decreased. There are some observations on the increase of mechanical strengths of composites as a result of adding nanoparticles (Potts et al. 2011). The increase of mechanical properties as a result of adding slight quantities of particles like graphene is simply understandable science that nanomaterials can transfer more stress and also improve the connections of the composite's components. (Young et al. 2012). Because graphene has flexural properties and a high specific surface, when a slight amount is mixed with a polymer properly it can increase the mechanical properties of the polymer specifically (Farsi and Younesi Kordkheili 2012). 
The method of adding a percentage of graphene has a great effect on the composite final properties (Sheshmani and Amiri 2013). Adding too much will cause the formation of graphene sheets over each other and lower the cohesiveness among the components of the composite. Additionally, it will not have a high increase in mechanical properties and if agglomeration occurs, the properties will decrease in strength.

Using the low percentages of graphene sheets in the composite was an advantage. Graphene has a higher free surface and higher tendency to react with components of the composites than carbon nanotubes. Thus, few graphene weight percentages are commonly used to prevent agglomeration and particles sticking together. In a study by Sheshmani and Amiri (2013), the addition of graphene nanoparticles (0.8 wt\%) to polypropylene wood fiber composites increased their mechanical strengths but increasing the graphene by 5 wt\%, decreased the mentioned properties (Sheshmani and Amiri 2013).

\section{Effect of the nanographene amount on flexural modulus}

The trend of changes of the composite's flexural modulus resulting from different levels of nanographene is displayed in Fig. 4. Figure 4 shows the highest and lowest average of the flexural modulus in the $0.5 \%$ sample (1432.62 MPa) and the $0 \%$ sample (1216.45 MPa), respectively.

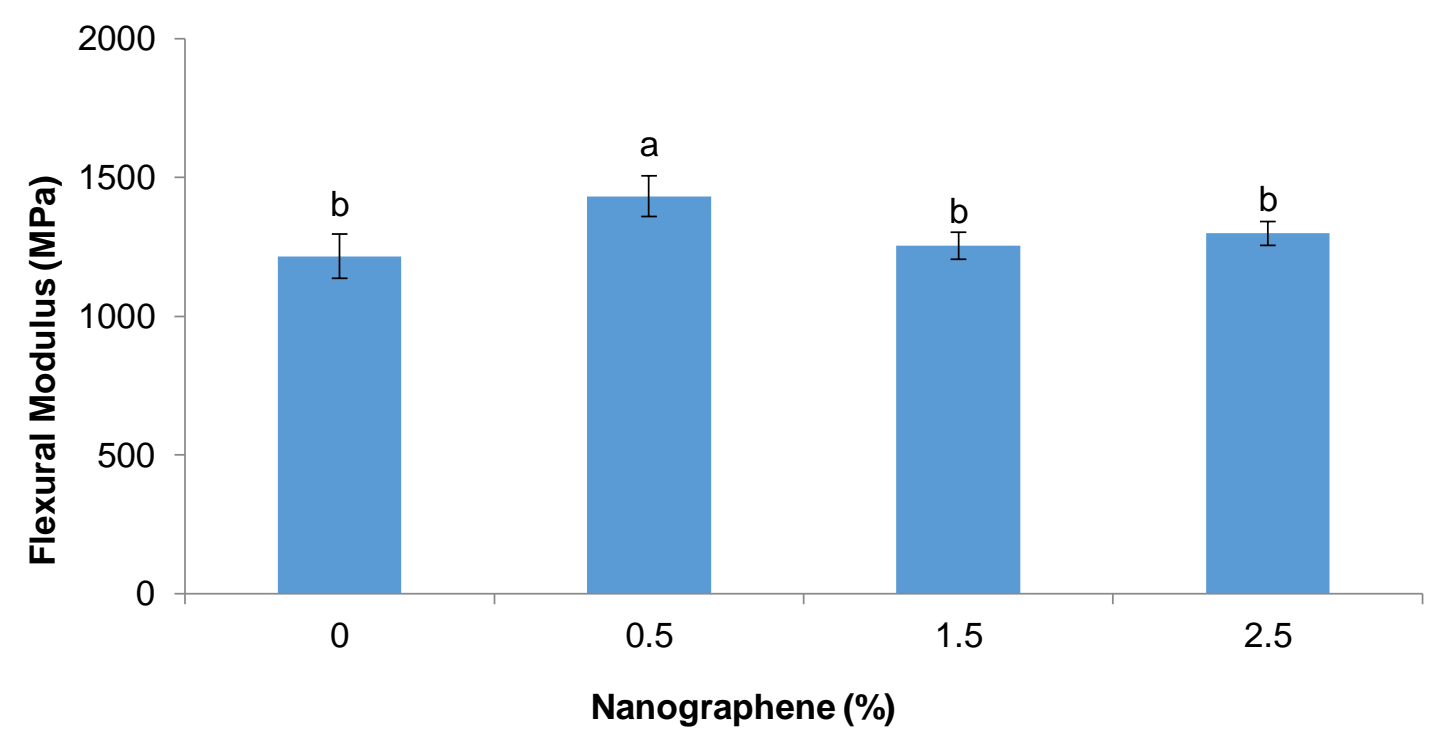

Fig. 4. Effect of the amount of nanographene on flexural modulus

In this research, it was observed that with the increase in the amount of nanographene by $0.5 \mathrm{wt} \%$, the composite flexural modulus first increased and then decreased. Sheshmani and Amiri showed that the greatest amount of modulus of elasticity was obtained at the $0.8 \%$ level and the modulus was less at higher percentages of graphene (Sheshmani and Amiri 2013). The graphene modulus of elasticity (1 TPa) was noticeably higher than the polypropylene modulus of elasticity.

Thus, the addition of graphene to wood-fiber composites caused an increase in the modulus. The reason for the decreased elastic modulus in higher percentages than $0.5 \%$ was attributed to the nonuniform distribution and agglomeration of nanoparticles in the composites (Kim and Macosko 2009). 
Some factors affected the performance of graphene in improving the mechanical properties of nanocomposites, such as the uniform distribution, alignment and exfoliation of graphene layers in the matrix.

\section{Effect of nanographene amount on the notched impact strength}

The trend of changes in the notched impact strength of the composite in different levels of nanographene is shown in Fig. 5. According to Fig. 5, the highest and lowest average of notched impact strengths was observed in the $0.5 \%$ sample $\left(33.3 \mathrm{~J} / \mathrm{m}^{2}\right)$ and the $2.5 \%$ sample $\left(24.3 \mathrm{~J} / \mathrm{m}^{2}\right)$, respectively.

In this research, it was observed that with the increase in the amount of nanographene $(0.5 \mathrm{wt} \%)$, the composite notched impact strength of the wood-plastic composite increased and then it decreased at the level of $2.5 \%$. The reduction of strength impact as the result of adding nanographene was predictable, because the presence of nanographene causes the fragility of composites and reduction of strengths towards those impacts. The presence of nanoparticles in the polymer matrix reduced the mobility of the chains and possibly the waste of their energies, increased the energy absorbed by the composite, and created highly tension spots. These spots can be places for failure and fracture (Han et al. 2008).



Fig. 5. Effect of the amount of nanographene on notched impact strength

\section{Effect of nanographene amount on water absorption and thickness swelling}

The trend of the composite water absorption changes resulting from different levels of nanographene is shown in Fig. 6. According Fig. 6, the lowest and highest average of water absorption was observed in the sample of $2.5 \%$ (with the amount of $0.16 \%$ ) and the $0 \%$ sample $(0.55 \%)$. The trend of changes of the composite's thickness swelling resulting from different levels of nanographene is displayed in Fig. 7. The lowest and highest averages of thickness swelling were observed in the $2.5 \%$ sample $(0.23 \%)$ and the $0 \%$ sample $(0.48 \%)$. 


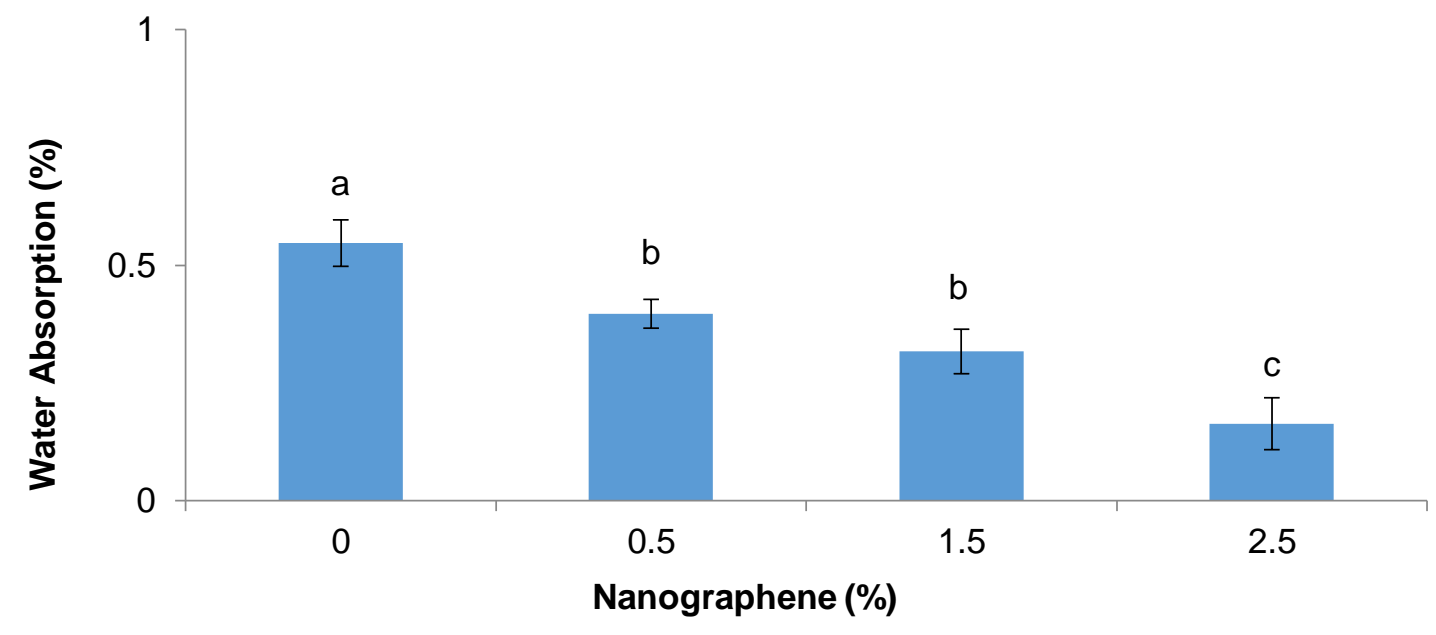

Fig. 6. The effect of nanographene amount on water absorption



Fig. 7. The effect of nanographene amount on thickness swelling

It was observed that with the increase in the nanographene amount from 0 to 2.5 wt $\%$, the water absorption and thickness swelling of the wood-plastic composite decreased. The reason for this issue was that the surfaces of nanographene are hydrophobic and this characteristic causes the inactivate state of humidity. Due to their hydrophobic nature, these materials have low moisture absorption. Thus, with the increase of mineral materials in the composite compound, the water absorption decreases (Lei et al. 2007). Water absorption and thickness swelling of the nanocomposite decreased with an increased amount of nanographene. It seems that the impenetrability of nanographene prevented the penetration of water into the polymeric matrix.

\section{Weight calorimetry}

The results of the level of the residual ash related to thermal decomposition are given in Table 2. With an increased level of nanographene, the level of remaining ash increased. 
Table 4. Temperature in Different Percentages of Weight Reduction of Nanocomposite at the Level of $20 \%$ Wood Flour and Different Percentages of Nanographene

\begin{tabular}{|c|c|c|c|c|c|c|c|c|}
\hline $\begin{array}{c}\text { Weight } \\
\text { Loss/ } \\
\text { Code }\end{array}$ & $\mathbf{5 \%}$ & $\mathbf{1 0 \%}$ & $\mathbf{2 0 \%}$ & $\mathbf{4 0 \%}$ & $\mathbf{6 0 \%}$ & $\mathbf{8 0 \%}$ & $\mathbf{9 0 \%}$ & $\begin{array}{c}\text { Remaining } \\
\text { Weight at } \\
\mathbf{6 0 0} \mathbf{C}\end{array}$ \\
\hline A 1 & 286 & 321 & 363 & 468 & 482 & 491 & 499 & 6.87 \\
\hline A 2 & 291 & 329 & 370 & 470 & 483 & 491 & 500 & 7.17 \\
\hline B 1 & 298 & 334 & 380 & 471 & 483 & 493 & 504 & 8.71 \\
\hline B 2 & 299 & 336 & 403 & 470 & 482 & 493 & 508 & 9.25 \\
\hline
\end{tabular}

Weight calorimetry analysis was used as a suitable instrument to determine the stability of the composite in different temperature conditions and to study the trend of analysis results from heating. Table 4 shows the temperature of destruction in different percentages of weight reduction and the remaining weight at the temperature of $600{ }^{\circ} \mathrm{C}$ for the wood-plastic nanocomposite. It was specified from the information in Table 4 that a $5 \%$ weight reduction occurred for the samples with no graphene at $286{ }^{\circ} \mathrm{C}$ and for the samples with $2.5 \%$ graphene at $399^{\circ} \mathrm{C}$. When the thermal temperature reached $321{ }^{\circ} \mathrm{C}$, in the sample with $0 \%$ nanographene, there was a $10 \%$ weight reduction. In the sample that contained $2.5 \%$ nanographene, this amount of weight reduction occurred at $336^{\circ} \mathrm{C}$. In the sample that contained $0 \%$ nanographene, the weight reduction occurred at $499{ }^{\circ} \mathrm{C}$, and in the sample with $2.5 \%$ nanographene it occurred at $508{ }^{\circ} \mathrm{C}$.

The results of the remaining ash (remaining weight) related to thermal analysis are observed in Table 4 . With the increase in percentage of nanographene, the weight reduction of the sample occurred at a higher temperature. Additionally, with the increased level of nanographene in different treatments, the level of ash increased. The level of the remaining ash in $600{ }^{\circ} \mathrm{C}$ in four samples of the composites during the use of 0 to $2.5 \%$ nanographene respectively was equal to $6.87 \%, 7.17 \%, 8.71 \%$, and $9.25 \%$,. Hemicellulose has the least stability against heating and its decomposing starts at $225{ }^{\circ} \mathrm{C}$. After hemicellulose, lignin and cellulose begin to decompose (Rowell 2005; Enayati et al. 2009). The primary decomposition of lignin starts earlier than cellulose (temperature decomposition of lignin is $250{ }^{\circ} \mathrm{C}$ and for cellulose is approximately $275^{\circ} \mathrm{C}$ ). However, as lignin shows a greater resistance against heating, the speed of its destruction is less than cellulose (temperature of maximum degradation of lignin is $500{ }^{\circ} \mathrm{C}$ and for cellulose is approximately $420{ }^{\circ} \mathrm{C}$ ) (Enayati et al. 2009; Yang et al. 2009). This lignin behavior results from the relatively weak bonds of alkyl groups connected to lignin aromatic rings at low temperature. At the same time, the stronger bonds existing in aromatic rings are degraded at higher temperatures and turn it into the most strengthened wood compound (Enayati et al. 2009; Kozlowski and Wladyka-Przybylak 2008).

\section{Effect of nanographene on thermal properties}

The thermal stability of composites is one of the important parameters for the process and applications of these types of materials. The production of some of the composites needs a mixing of fibers and the matrix at high temperature. Thus, the thermal destruction of lignocellulosic materials causes unfavorable effects on the composite properties. The effect of graphene percentage on weight loss percentage of waste polyethylene-wood flour composite at the level of $20 \%$ flour during the heating time (from 25 to $650^{\circ} \mathrm{C}$ ) is shown in Fig. 8. In the beginning, one primary weight reduction, less than 
$165^{\circ} \mathrm{C}$ was observed, which was due to losing the humidity of composites. Of course, it was not very clear in the diagram because it was only a slight amount. Additionally, it was clear that the reduction of the weight of the composite with the lack of graphene was almost smoother than the other three samples. This was possible due to the positive impact of graphene in postponing the destruction of the polymer matrix.

In the curves related to the composite, two stages were seen in weight reduction. In the first stage, which encompassed the temperature of approximately 300 to $500{ }^{\circ} \mathrm{C}$, it was related to wood fibers. The second stage that ranged from approximately 500 to $650{ }^{\circ} \mathrm{C}$, was related to thermal destruction of the polymer, which has a greater thermal stability compared to wood. The primary destruction that started at $270{ }^{\circ} \mathrm{C}$ and continues to $375^{\circ} \mathrm{C}$ was related to the wood flour degradation.

In the first stage of destruction, there was a clear point of weight reduction percentage or thermal destruction with an increased percentage nanographene that showed a positive effect of graphene in improving the thermal resistance of the composite in the destruction of wood flour. After $375^{\circ} \mathrm{C}$, the second stage of destruction began, which was mainly related to matrix degradation. In this stage, the distance between diagrams became greater because of the matrix degradation of composites containing nanographene at higher temperatures. The occurrence of this phenomenon was possibly due to the fact that the nanographene postponed the decomposition of the produced volatile matters.

In general, the results showed that with increased nanographene, the thermal stability of samples increased and as nanographene increased, nanocomposite began to degrade at higher temperatures. This means that the specimen will lose weight at higher temperatures and this result was in agreement with the results of other researchers (Zhu et al. 2002; Gilman et al. 2006). Of course, the effect of nanographene on improving the thermal stability depends on conditions such as the type of polymer and conditions of processing. It is worth noting that nanographene at higher temperature increases the thermal stability (Nourbakhsh et al. 2010).

The most important factor in composite thermal stability is the formation of a noncombustible coal layer in the composite. Therefore, the special high level and the formed layer have a great effect on composite thermal stability (Khosravian 2010).

\section{Morphology by SEM}

In this research, the microstructures present on the surfaces of composite fracture were studied. Using the images obtained from SEM, it was possible to observe the suitable distribution and agreement between the filler and matrix. The created spaces signified the weak connection between the fibers and matrix. This meant that by applying tension and pressure, fibers were separated from its surface due to weak connections with the matrix. In this part, the authors will study the surfaces of the fracture of the built composites.

In this research, composite fracture with the presence of $3 \mathrm{wt} \%$ coupling agent showed almost an integrated environment. Fibers were encompassed to some extent by the matrix. The cohesion between these two phases is to the extent that fewer fibers were removed from their own places. As it was observed, the polyethylene matrix to a great extent surrounded the cellulose fibers and created a proper link with them, but despite the suitable cohesion, some small holes still could be seen. (Fig. 8).

Figure 8 shows images related to the surfaces of the samples' fractures, containing $20 \%$ wood flour and nanographene at 4 levels: $0,0.5,1.5$, and $2.5 \%$. Improving the mechanical properties through the addition of $0.5 \%$ nanographene was shown in the section on mechanical properties, and has been demonstrated in this section via electronic 
microscope images and a noticeable improvement in the distribution and coupling between the fibers and matrix at the surface is observable.
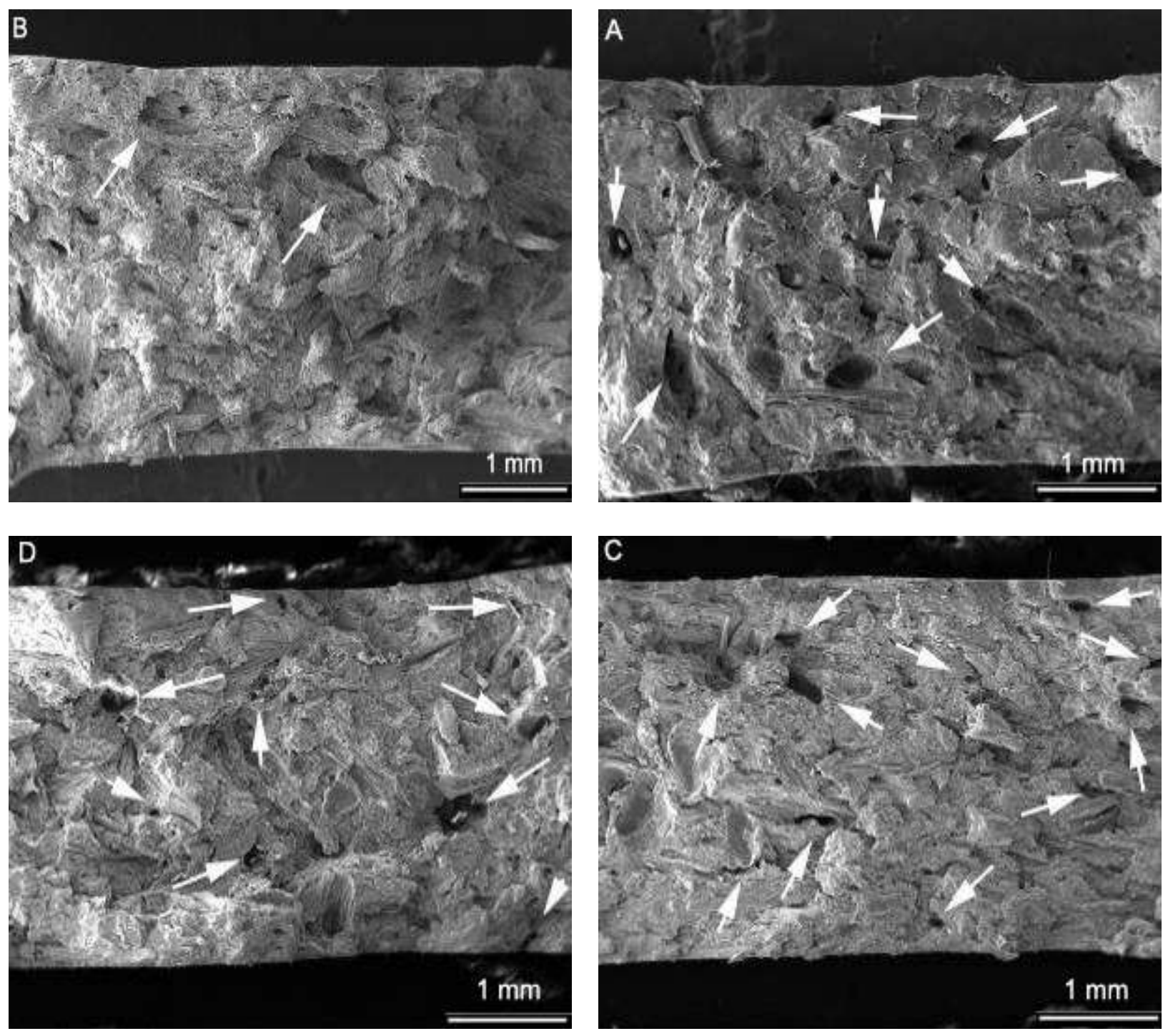

Fig. 8. SEM images of composite containing $20 \%$ wood flour: A (0\%), B (0.5\%), C (1.5\%), and D $(2.5 \%)$ nanographene; arrows show holes in SEM images

Figure 8(A) illustrates non-nanographene samples that were easily broken with minimal load and the fibers moved out easily from the polymer matrix and made some holes at the surface of the samples. In Fig. 8(B), there are few empty spaces (holes) between the lignocellulosic material and polymeric matrix as well as more uniformity and more coherence in the composite that can be observed. This showed a better dispersion of the fibers inside the matrix and the creation of a strong connection between the polymer and filler. Thus, wood fibers were connected to the polymer matrix well and caused a lack of separation of fibers. This showed the suitable coupling among the components of the composite with each other. The strong cohesion in the intersection between fibers and polymer matrix (which is related to capsulation of fibers with polyethylene) (Chaharmahali et al. 2014) was also confirmed in the mechanical section, resulting in improvement in the mechanical properties. 
Figure 8(D and E) shows the surface of samples' fracture containing 1.5 and $2.5 \%$ of graphene in which many holes at the fracture surface are observable. This event caused the reduction of mechanical properties. In fact, the addition of graphene at high levels resulted in a non-uniform distribution and to a certain extent caused agglomeration that was visible in Fig. 9(A, B, and C). Agglomeration creates the blank spaces in a composite and leads to the reduction of mechanical strengths compared to the samples made with a lower percentage of nanographene.

The results obtained from the SEM images of the samples containing 1.5 and $2.5 \%$ nanographene indicate the improper distribution and presence of their agglomeration in the samples (Fig. 9). Thus, when tension is applied on the samples, as a result of agglomerations, these tensions are not transferred and due to the concentration of tension in this point, the strength characteristics of composites decrease.


Fig. 9. FE-SEM image of composite containing $20 \%$ of wood flour: $1.5 \%(A)$ and $2.5 \%(B)$ of nanographene and $2.5 \%$ of agglomerated nanographene $(\mathrm{C})$ 
The presence of nanographene exceeded a certain limit in the polymer matrix, which caused the reduction of movability of polymer chains and if force is applied on them they will have no possibility to waste the force. Consequently, the strengths will decrease. In contrast, due to the presence of nanographene agglomerations in the samples (Fig. 9) during force application, the concentration of tension in these spots will be observed. This will cause the reduction of strengths. For this reason, the results showed that by increasing the amount of nanographene, the composite strengths of wood-plastic decreased, which was in agreement with the results obtained by other researchers (Han et al. 2008).

\section{FTIR spectrum}

Comparison of the effect of different nanographene percentages on the FTIR spectrum of recycled polyethylene/spruce wood flour at the $20 \%$ level is shown in Fig. 10. It was observed that in the range of 3300 to $3450 \mathrm{~cm}^{-1}$, the $\mathrm{O}-\mathrm{H}$ tensile bond was blocked, and this indicated that the water absorption and thickness swelling of samples would have decreased. In the range of 2800 to $2900 \mathrm{~cm}^{-1}$, the C-H tensile bond (ethylene and methylene groups) was concentrated.

In the sample containing $0.5 \%$ of nanographene in the range of 2800 to $2900 \mathrm{~cm}^{-1}$, the $\mathrm{C}-\mathrm{H}$ tensile bond decreased in intensity and width. This event was most likely due to the balanced distribution of particles and the further blockage of dual bondings of ethylene groups in all areas.

In the higher percentages of nanographene, their dispersion was unbalanced, and these materials were likely to be agglomerated in some points, and the amount of blockage was also less.

It was observed in the electronic microscope images that with $0.5 \%$ nanographene the amount of pores was much less than higher percentages.

The absorbance values corresponding to chemical bonds in the wood-plastic composites with different percentages of nanographene showed that $(\mathrm{C}=\mathrm{O})$ the carbonyl group's contribution to the spectrum was changed. In fact, carbonyl groups were blocked, their intensity decreased, and the spectrum was shifted upwards. The changes in absorbance of carbonyl groups in different treatments is apparent in the range of 1550 to $1750 \mathrm{~cm}^{-1}$. In the $0.5 \%$ nanographene sample, the tensile bond of $\mathrm{C}=\mathrm{O}$ in the range of 1550 to $1750 \mathrm{~cm}^{-1}$ made a more intensive carbonyl bond and this phenomenon increased the mechanical features with the addition of $0.5 \%$ of nanographene.

The range of 1200 to $1280 \mathrm{~cm}^{-1}$ was related to $\mathrm{C}-\mathrm{O}-\mathrm{C}$ groups that were again blocked and move upward. This group made stronger bonds in the sample containing $0.5 \%$ of nanographene. At the range of 1260 to $1300 \mathrm{~cm}^{-1}$ the intensity was higher.

In the FTIR spectrum of nanographene, the absorbance band located at $3414 \mathrm{~cm}^{-1}$ can be allocated to the $\mathrm{O}-\mathrm{H}$ strong stretching vibration. Additionally, in the range of 2800 to $3000 \mathrm{~cm}^{-1}$, there was a $\mathrm{C}-\mathrm{H}$ stretching vibration.

In the FTIR spectrum of nanographene, the peak at the range of 1079 to $1100 \mathrm{~cm}^{-1}$ is a $\mathrm{C}-\mathrm{O}$ bond and the peak at $1723 \mathrm{~cm}^{-1}$ was the $\mathrm{C}=\mathrm{O}$ double bond in the carboxylic acid group (Bosch-Navarro et al. 2012; Gao et al. 2012). The obvious peak in the range of 1580 to $1600 \mathrm{~cm}^{-1}$ shows asymmetric tensile vibration of the double bond of the $\mathrm{C}=\mathrm{C}$ group (Chowdhury and Balasubramanian 2014). The intensity of absorbance in the range of 1200 to $1280 \mathrm{~cm}^{-1}$ was related to $\mathrm{C}-\mathrm{O}-\mathrm{C}$ groups in epoxide. 


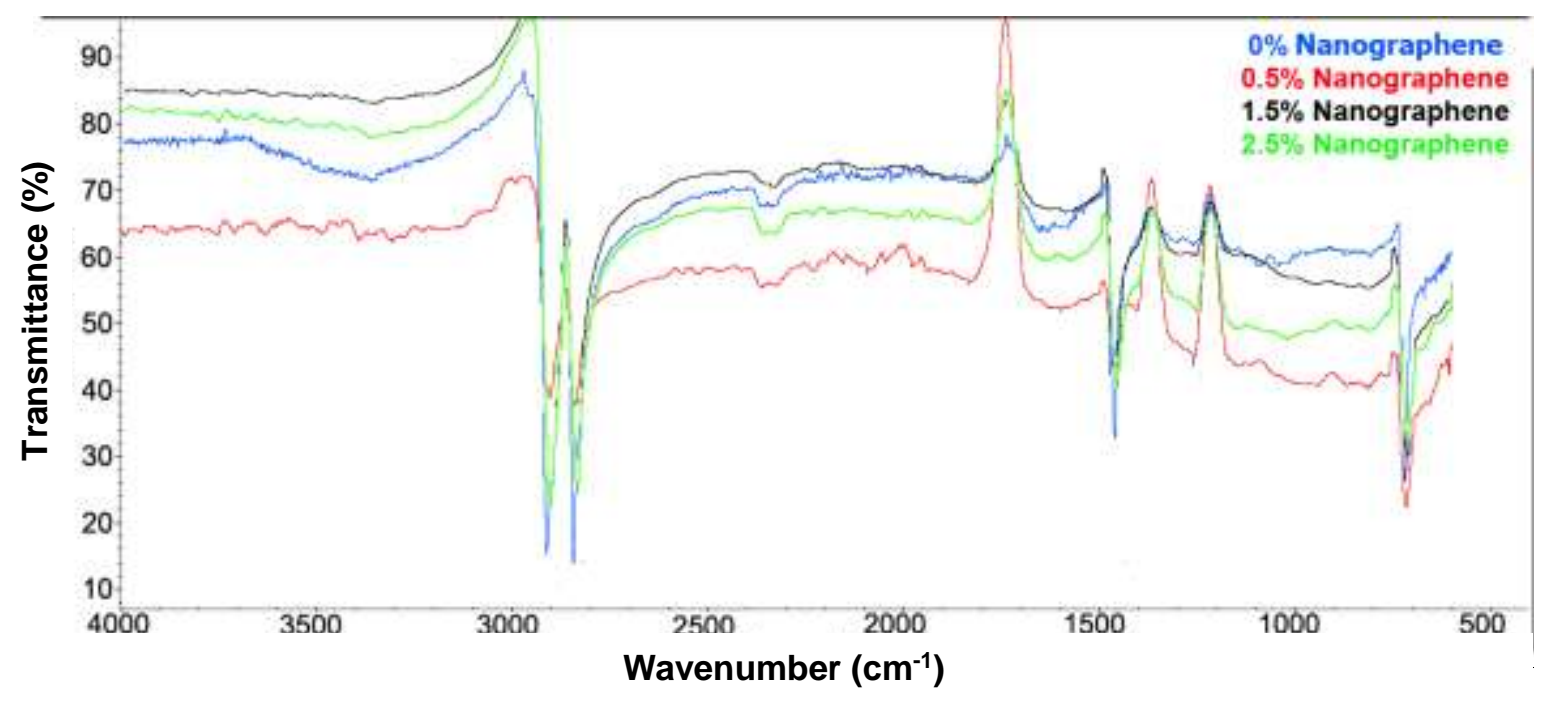

Fig. 10. FTIR spectrum of the $20 \%$ wood flour sample and different percentages of nanographene

\section{CONCLUSIONS}

The effect of nanographene was studied relative to the physical, mechanical, thermal and morphological features of a nanocomposite made of wood flour and recycled polyethylene, and the following results were obtained:

1. With an increase of nanographene amount of $0.5 \mathrm{wt} \%$, the tensile and flexural strength, flexural and tensile modulus, and notched strength impacts of the composites increased. The addition of $2.5 \mathrm{wt} \%$ of nanographene decreased these properties.

2. With the increase of nanographene amount by $2.5 \mathrm{wt} \%$, the water absorption and thickness swelling of composites decreased.

3. With increased nanographene amount, the level of remaining ash and the thermal stability also increased.

4. The SEM images showed that the samples containing $0.5 \%$ of nanographene had less holes and more smoothness compared with the other samples.

\section{REFERENCES CITED}

Abad, M., Ares, A., Barral, L., Cano, J., Diez, F., García-Garabal, S., Lopez, J., and Ramirez, C. (2004). "Effects of a mixture of stabilizers on the structure and mechanical properties of polyethylene during reprocessing," Journal of Applied Polymer Science 92(6), 3910-3916. DOI: 10.1002/app.20420

An, J. E., Jeon, G. W., and Jeong, Y. G. (2012). "Preparation and properties of polypropylene nanocomposites reinforced with exfoliated graphene," Fibers and Polymers 13(4), 507-514. DOI: 10.1007/s12221-012-0507-z 
Ansari, S., and Giannelis, E. P. (2009). "Functionalized graphene sheet-Poly (vinylidene fluoride) conductive nanocomposites," Journal of Polymer Science Part B: Polymer Physics 47(9), 888-897. DOI: 10.1002/polb.21695

ASTM D256-10 (2010). "Standard test methods for determining the Izod pendulum impact resistance of plastics," ASTM International, West Conshohocken, PA, USA.

ASTM D638-10 (2010). "Standard test method for tensile properties of plastics," ASTM International, West Conshohocken, PA, USA.

ASTM D747-10 (2010). "Standard test method for flexural properties of unreinforced and reinforced plastics and electrical insulating materials," ASTM International, West Conshohocken, PA, USA.

ASTM D1238-04 (2004). "Standard test method for melt flow rates of thermoplastics by extrusion plastometer," ASTM International, West Conshohocken, PA, USA.

ASTM D7031-10 (2010). "Standard guide for evaluating mechanical and physical properties of wood-plastic composite products," ASTM International, West Conshohocken, PA, USA.

Balandin, A. A., Ghosh, S., Bao, W., Calizo, I., Teweldebrhan, D., Miao, F., and Lau, C. N. (2008). "Superior thermal conductivity of single-layer graphene," Nano Letters 8(3), 902-907. DOI: 10.1021/n10731872

Bengtsson, M., Le Baillif, M., and Oksman, K. (2007). "Extrusion and mechanical properties of highly filled cellulose fibre-polypropylene composites," Composites Part A: Applied Science and Manufacturing 38(8), 1922-1931. DOI: 10.1016/j.compositesa.2007.03.004

Bosch-Navarro, C., Coronado, E., Martí-Gastaldo, C., Sánchez-Royo, J. F., and Gómez, M. G. (2012). "Influence of the $\mathrm{pH}$ on the synthesis of reduced graphene oxide under hydrothermal conditions," Nanoscale 4(13), 3977-3982. DOI: 10.1039/C2NR30605K

Cardinali, M., Valentini, L., Kenny, J. M., and Mutlay, İ. (2012). "Graphene based composites prepared through exfoliation of graphite platelets in methyl methacrylate/poly (methyl methacrylate)," Polymer International 61(7), 1079-1083. DOI: $10.1002 /$ pi.4180

Chaharmahali, M., Hamzeh, Y., Ebrahimi, G., Ashori, A., and Ghasemi, I. (2014). "Effects of nanographene on the physico-mechanical properties of bagasse/polypropylene composites," Polymer Bulletin 71(2), 337-349. DOI: 10.1007/s00289-013-1064-3

Chowdhury, S., and Balasubramanian, R. (2014). "Recent advances in the use of graphene-family nanoadsorbents for removal of toxic pollutants from wastewater," Advances in Colloid and Interface Science 204, 35-56. DOI: 10.1016/j.cis.2013.12.005

Dato, A., Lee, Z., Jeon, K. J., Erni, R., Radmilovic, V., Richardson, T. J., and Frenklach, M. (2009). "Clean and highly ordered graphene synthesized in the gas phase," Chemical Communications 40, 6095-6097.

Ghani, A., and Hafizuddin, M. (2011). "The comparison of water absorption analysis between counterrotating and corotating twin-screw extruders with different antioxidants content in wood plastic composites," Advances in Materials Science and Engineering 2011, Article ID 406284. DOI: 10.1155/2011/406284

Enayati, A. A., Hosseinaei, O., Wang, S., Mirshokraie, S. A., and Tajvidi, M. (2009). "Thermal properties of wood-plastic composites prepared from hemicelluloseextracted wood flour," Iranian Journal of Polymer Science and Technology 22(3), 171-181. 
Farsi, M., and Younesi Kordkheili, H. (2012). "Effect of single wall carbon nanotubes on physical and mechanical properties of wood fiber- LDPE composites," Journal of Forest and Wood Products, Iranian Journal of Natural Resources 65(2), 169-186.

Gao, C., Yu, X. Y., Xu, R. X., Liu, J. H., and Huang, X. J. (2012). “AlOOH-reduced graphene oxide nanocomposites: One-pot hydrothermal synthesis and their enhanced electrochemical activity for heavy metal ions," ACS Applied Materials \& Interfaces 4(9), 4672-4682. DOI: 10.1021/am3010434

Gao, H., Song, Y. M., Wang, Q. W., Han, Z., and Zhang, M. L. (2008). "Rheological and mechanical properties of wood fiber-PP/PE blend composites," Journal of Forestry Research 19(4), 315-318. DOI: 10.1007/s11676-008-0057-9

Gilman, J. W., Harris, R. H., Shields, J. R., Kashiwagi, T., and Morgan, A. B. (2006). “A study of flammability reduction mechanism of polystyrene-layered silicate nanocomposites: Layered silicate reinforced carbonaceous char," Polymers for Advanced Technologies 17(4), 263-271. DOI: 10.1002/pat.682

Han, G., Lei, Y., Wu, Q., Kojima, Y., and Suzuki, S. (2008). "Bamboo-fiber filled high density polyethylene composites; effect of coupling treatment on nanoclay," Journal of Polymer Environment 16(2), 123-130. DOI: 10.1007/s10924-008-0094-7

Hornsby, P. R., Hinrichsen, E., and Tarverdi, K. (1997). "Preparation and properties of polypropylene composites reinforced with wheat and flax straw fibres: Part I fibre characterization," Journal of Materials Science 32(2), 443-449. DOI:

10.1023/A:1018521920738

Khosravian, B. (2010). Studying Mechanical, Physical, Thermal and Morphological Characteristics of Hybrid Composites of Polypropylene/Wood Flour/Wollastonite, Master's Thesis, Faculty of Agriculture and Natural Resources, University of Tehran, Iran.

Kim, H., and Macosko, C. W. (2009). "Processing-property relationships of polycarbonate/graphene composites," Polymer 50(15), 3797-3809. DOI: 10.1016/j.polymer.2009.05.038

Klason, C., Kubat, J., and Strömvall, H. E. (1984). "The efficiency of cellulosic fillers in common thermoplastics Part 1. Filling without processing aids or coupling agents," International Journal of Polymeric Materials 10(3), 159-187. DOI: $10.1080 / 00914038408080268$

Kord, B. (2016). "Effect of filler content and compatibilizer on thermal properties of wood flour-HDPE composites," Journal of Wood \& Forest Science and Technology 22(4), 187-203.

Kozlowski, R., and Wladyka-Przybylak, M. (2008). "Flammability and fire resistance of composites reinforced by natural fibers," Polymers for Advanced Technologies 19(6), 446-453. DOI: 10.1002/pat.1135

Kuilla, T., Bhadra, S., Yao, D., Kim, N. H., Bose, S., and Lee, J. H. (2010). "Recent advances in graphene based polymer composites," Progress in Polymer Science 35(11), 1350-1375. DOI: 10.1016/j.progpolymsci.2010.07.005

Le Baillif, M., and Oksman, K. (2009). "The effect of processing on fiber dispersion, fiber length, and thermal degradation of bleached sulfite cellulose fiber polypropylene composites," Journal of Thermoplastic Composite Materials 22(2), 115-133. DOI: $10.1177 / 0892705708091608$

Najafi, S. K. (2013). "Use of recycled plastics in wood plastic composites-A review," Waste Management 33(9), 1898-1905. DOI: 10.1016/j.wasman.2013.05.017 
Nourbakhsh, A., Karegarfard, A., Ashori, A., and Nourbakhsh, A. (2010). "Effects of particle size and coupling agent concentration on mechanical properties of particulate-filled polymer composites," Thermoplastic Composite Materials 23(2), 169-174. DOI: $10.1177 / 0892705709340962$

Pinheiro, L., Chinelatto, M., and Canevarolo, S. (2004). "The role of chain scission and chain branching in high density polyethylene during thermo-mechanical degradation," Polymer Degradation and Stability 86(3), 445-453. DOI: 10.1016/j.polymdegradstab.2004.05.016

Potts, J. R., Dreyer, D. R., Bielawski, C. W., and Ruoff, R. S. (2011). "Graphene-based polymer nanocomposites," Polymer 52(1), 5-25. DOI:

10.1016/j.polymer.2010.11.042

Rowell, R. M. (2005). Handbook of Wood Chemistry and Wood Composite, $2^{\text {nd }}$ Edition, CRC Press, Boca Raton, FL, USA.

Saheb, D. N., and Jog, J. P. (1999). "Natural fiber polymer composites: A review," Advances in Polymer Technology: Journal of the Polymer Processing Institute 18(4), 351-363. DOI:10.1002/(SICI)1098-2329(199924)18:4<351::AID-ADV6>3.0.CO;2-X

Sheshmani, S., and Amini, R. (2013). "Preparation and characterization of some graphene based nanocomposite materials," Carbohydrate Polymers 95(1), 348-359. DOI: 10.1016/j.carbpol.2013.03.008

Tripathy, S. S., Di Landro, L., Fontanelli, D., Marchetti, A., and Levita, G. (2000). "Mechanical properties of jute fibers and interface strength with an epoxy resin," Journal of Applied Polymer Science 75(13), 1585-1596. DOI: 10.1002/(SICI)1097-4628(20000328)75:13<1585::AID-APP4>3.0.CO;2-Q

Yang, H., Shan, C., Li, F., Zhang, Q., Han, D., and Niu, L. (2009). "Convenient preparation of tunably loaded chemically converted graphene oxide/epoxy resin nanocomposites from graphene oxide sheets through two-phase extraction," Journal of Materials Chemistry 19(46), 8856-8860. DOI: 10.1039/B915228H

Young, R. J., Kinloch, I. A., Gong, L., and Novoselov, K. S. (2012). "The mechanics of graphene nanocomposites: A review," Composites Science and Technology 72(12), 1459-1476. DOI: 10.1016/j.compscitech.2012.05.005

Zafeiropoulos, N. E., Baillie, C. A., and Matthews, F. L. (2001). "A study of transcrystallinity and its effect on the interface in flax fibre reinforced composite materials," Composites Part A: Applied Science and Manufacturing 32(3-4), 525-543. DOI: $10.1016 / \mathrm{S} 1359-835 \mathrm{X}(00) 00058-0$

Zhu, J., Start, P., Mauritz, K. A., and Wilkie, C. A. (2002). "Silicon-methoxide-modified clays and their polystyrene nanocomposites," Journal of Polymer Science Part A: Polymer Chemistry 40(10), 1498-1503. DOI: 10.1002/pola.10231

Article submitted: June 6, 2019; Peer review completed: November 3, 2019; Revised version received: December 12, 2109; Accepted: December 14, 2019; Published: January 6, 2020.

DOI: $10.15376 /$ biores.15.1.1233-1251 